\title{
Prognostic Indicators and Short Term Outcomes for Operated Patients with Peritonitis: Prospective Cohort Hospital Based Study in Northern Tanzania
}

\author{
Nassib D Msuya ${ }^{1,2, *}$, Julius P Aloyce ${ }^{2}$, David Msuya ${ }^{1,2}$, Kondo Chilonga ${ }^{1,2}$, Ayesiga Herman ${ }^{1,2}$, and Samuel Chugulu ${ }^{1,2}$ \\ ${ }^{1}$ Department of General Surgery, Kilimanjaro Christian Medical University College, Moshi, Tanzania \\ ${ }^{2}$ Department of General Surgery, Kilimanjaro Christian Medical Centre, Moshi, Tanzania
}

*Corresponding author: Nassib D Msuya, Department of General Surgery, Kilimanjaro Christian Medical University College, P.O Box 2240, Moshi, Tanzania, Tel: +255768146717; E-mail: dmsuya@yahoo.com

Received: 21 Feb, 2021 | Accepted: 22 Apr, 2021 | Published: 28 Apr, 2021

Citation: Msuya ND, Aloyce JP, Msuya D, Chilonga K, Herman A, et al. (2021) Prognostic Indicators and Short Term Outcomes for Operated Patients with Peritonitis: Prospective Cohort Hospital Based Study in Northern Tanzania. J Surg Open Access 7(2): dx.doi.org/10.16966/24700991.235

Copyright: (C) 2021 Msuya ND, et al. This is an open-access article distributed under the terms of the Creative Commons Attribution License, which permits unrestricted use, distribution, and reproduction in any medium, provided the original author and source are credited.

\begin{abstract}
Background: Peritonitis is one of the most common surgical emergencies all over the world and is associated with significant complications and mortality. The spectrum of aetiology of peritonitis differs between high income countries and low income countries. Majority of the patients present late with purulent peritonitis and septiceamia. Surgical treatment of peritonitis is highly demanding and very complex, however, if the outcome in these patients can be correctly predicted, then better management can be instituted in order to achieve optimal patient's care and hence improve treatment outcome.
\end{abstract}

Methods: Prospective cohort hospital based study was conducted among patients admitted due to peritonitis at Kilimanjaro Christian Medical Center (KCMC) from October 2018 to March 2019. Documentary review and interview methods were employed to obtain data using electronic structured questionnaire. Data was summarized using median, Inter-Quartile Range (IQR), frequency and percentage. Both bivariate and multivariate logistic regression analyses were used to identify prognostic indicators for post-operative complications and mortality. A $95 \% \mathrm{Cl}$ and $\mathrm{P}<0.05$ used for significance test.

Results: The study enrolled 70 patients with predominance of male, giving a male to female ratio of 4.1:1. A total number of 33(47.1\%) developed complications and $16(22.9 \%)$ died. Only $1(1.43 \%)$ patient presented to the hospital within 24 hours since the onset of illness. Delay in care, longer duration of operation, and low potassium were the prognostic indicators noted to have influence on short term complications. The major influence for mortality were comorbidity (AOR=3.02; 95\% Cl: 2.25-42.90) and postoperative complications (dyselectrolaemia) with (AOR=9.27; $95 \% \mathrm{Cl}$ : $1.21-$ 70.83).

Conclusion: Mortality and complications resulted from peritonitis is unacceptably high. Delay in care, longer duration of operation and preoperative low serum potassium levels were the prognostic indicators for the post-operative complications. Comorbidity and postoperative complications such as dyselectrolaemia had influence for the mortality. Correct prediction of these adverse outcomes will help to institute better management for the patients with peritonitis.

Keywords: Peritonitis; Prognostic indicators; Short term outcomes

Abbreviations: AOR: Adjusted Odds Ratio; APACHE: Acute Physiology And Chronic Health Evaluation; ARDS: Acute Respiratory Distress Syndrome; ASA: American Society of Anaesthesia; Cl: Confidence Interval; COR: Crude Odds Ratio; GIT: Gastrointestinal Tract; Hb: Haemogobin; Hct: Haematocrit; HIV: Human Immunodeficiency Virus; ICU: Intensive Care Unit; IQR: Inter-quartile range; KCMC: Kilimanjaro Christian Medical Center; KCMUCo: Kilimanjaro Christian Medical University College; MOSF: Multiple Organ System Failure; PI: Principal Investigator; PR: Pulse Rate; PUD: Peptic Ulcer Disease; RR: Respiratory Rate; SIRS: Systematic Inflammatory Response Syndrome; SPSS: Statistical Package for Social Sciences; TLC: Total Leucocyte Counts.

\section{Background}

Peritonitis is defined as an inflammatory process of the peritoneum caused by introduction of infections into the otherwise sterile peritoneal environment which might be chemical irritants/agents such as bacteria, fungi, virus, talc, drugs, granulomas, and foreign bodies $[1,2]$. Peritonitis is a frequently encountered emergence and remains a significant cause of postoperative complications and mortality which usually requires emergency surgery. Risk evaluation in peritonitis can predict outcomes, direct treatment planning and aid in the conduct of surgical audits; ultimately leads to improved results 
in terms of reducing complications and mortality. Peritonitis is one of the most common surgical emergencies all over the world and is associated with significantly morbidity and mortality $[3,4]$.

Currently in developing countries the mortality due to peritonitis is reported to be between 13-43\%, thus becoming the dominant cause of death due to surgical infections despite the great progress in intensive care support, antimicrobial therapy and surgical techniques. Timely prognostic evaluation of peritonitis will not only provide desirable categorization of disease severity but also correctly predict the outcome hence more aggressive and better therapeutic management can be instituted $[5,6]$. In Tanzania a study done at Bugando Medical Centre (BMC) in 2015 showed the overall mortality was $15.46 \%$ with overall postoperative complications of $36.08 \%[5,6]$.

Regardless of advancement in various supportive and therapeutic interventions such as intensive care support, antimicrobial therapy and surgical techniques, the management of peritonitis is still difficult and puts a big challenge to clinicians [7].

Early prognostic evaluation of peritonitis is desirable to provide objective classification of the severity of the disease and hence select high risk patients for more aggressive therapeutic procedures. Therefore this study aimed at exploring the wide range of prognostic indicators which determine the short term outcome for operated patients with peritonitis so as to identify factors responsible for the poor outcome and specifically address them in the context of reducing poor outcomes among operated patients with peritonitis.

\section{Methods}

\section{Study design and setting}

This was a prospective cohort study conducted from October 2018 to March 2019 at the department of General Surgery at KCMC in Moshi in the Kilimanjaro region. KCMC is a Northern Zone Consultant Hospital in Tanzania. The hospital receives referred patients from northern and central regions namely Arusha, Manyara, Tanga, Dodoma, Singida and districts from the Kilimanjaro region. The population served is more than 15 million people.

\section{Study population}

All patients admitted at KCMC due to peritonitis at surgical department who met inclusion criteria were enrolled in the study.

\section{Sample size and sampling procedure}

A minimum sample size of 70 was estimated using Fischer's formula based on the study which was done at Bugando Medical centre in Tanzania in 2015 found $36.1 \%$ of short term complication among patients with peritonitis [6].

Consecutive sampling procedure was employed to obtain 70 study participants; where one case was enrolled after the other consecutively until the required sample size met.

\section{Data collection tool, methods and study procedures}

Electronic structured questionnaire was used for data collection from the patient files. Pre-testing was done among 10 patients, the findings from pre-testing was used to test the validity and reliability of the study tool whereby adjustment was done accordingly.

This study employed documentary review and interview methods to obtain data from patient files and patients respectively, hence filling structured questionnaires. Principal investigator of the study and one trained research assistant used the structured questionnaire for data abstraction.
Patients were admitted to general surgical ward and Surgical Intensive Care Unit (SICU) through outpatient clinic, emergency department and other departments. On arrival to the wards based on history, physical examination, laboratory tests and radiological findings; a provisional diagnosis of peritonitis was reached. After resuscitation and stabilization, patients were taken to theatre for laparotomy.

The vital signs were taken and clinical examination was conducted regularly every day following the initial visit to look for complications until patient discharge or death. Complications during the follow up period were determined by identification of one or more of the following complications: Surgical site infections, Postoperative septiceamia, enterocutaneous fistula, surgical site infections, dyselectrolaemia, burst abdomen and reoperation. Patients were followed up till their discharge and then weekly during the outpatient visits. An appointment was made by phone. The study end point was reached at the $30^{\text {th }}$ day postoperatively following the first operation or death. Variables for the study were obtained from patient data and case notes as in the data sheet.

\section{Data management and analysis}

The collected data were crosschecked for completeness and validity following study eligibility. The valid cases were entered into Statistical Packed for the Social Science (SPSS Version 23.0) with help of a trained data clerk. Data backup was maintained daily and secured with password for unauthorized person. The data was then cleaned by checking for entry errors and categorization of the study variables following the standardized approach for clinical parameters' classifications including haemoglobin, urea, creatinine, sodium, potassium and Total Leucocyte Counts (TLC).

Descriptive analysis was done to summarize the numerical data using median and Inter-Quartile Range (IQR), while categorical variables were summarized using frequency and percentage. Bivariate Logistic regression analysis for crude odds ratios was applied to determine the strength of association between outcome variables (Complications and mortality) and the prognostic indicators. Multivariate logistic analysis was applied to control confounders and effects modifiers towards development of post-operative complications and mortality among patients with peritonitis. A 95\% confidence interval and $\mathrm{p}<0.05$ was used to identify significant prognostic indicators. The findings were presented using figures and tables.

\section{Results}

A total of 83 patients were managed for peritonitis during the study period. Thirteen (13 cases) did not meet the study criteria and were excluded from the study. Thus, a total 70 participants were enrolled in the study. Of which 49 (70\%) developed post operative complications (Figure 1).

\section{Socio-demographic characteristics of the study participants}

Of 70 patients took place in the study, the median age was 41 years with inter-quartile range between 22 to 56 years old. Majority $81.4 \%(n=57)$ were male and $18.6 \%(n=13)$ female. About $61.4 \%$ $(n=43)$ had primary education and nearly two third $65.7 \%(n=46)$ were unemployed. More than half $52.9 \%(n=37)$ of the patients were residing in other Districts of Kilimanjaro region. Ten $14.3 \%$ reported to have been smoking and $24.3 \%(\mathrm{n}=17)$ drinking alcohol (Table 1).

The short term outcomes for operated patients with peritonitis at $\mathrm{KCMC}$ 
Regarding the distribution of short term outcome for operated patients with peritonitis $30 \%$ had successful operation without presented with short term complications, $47.1 \%$ had complications and $22.9 \%$ died. The most common complication presented was septicemia $55.7 \%$ followed by dyselectrolaemia $21.4 \%$, surgical infection $18.6 \%$, enterocutaneous fistula, reoperation $10 \%$ and burst abdomen $5.7 \%$. Having mortality of $22.9 \%$ implies about 2 patients in 10 patients with peritonitis die after operation (Figure 2).

\section{Prognostic indicators for complications among operated patients with peritonitis}

Complications comprised of septicemia, dyselectrolaemia, surgical infection, enterocutaneous fistula, reoperation, and burst abdomen.
Prognostic indicators for complications were categorized into nonlaboratory and laboratory parameters as follows:

Table 2 shows non-laboratory indicators for complications. Complications were more common among patients aged 50 years or below $57.4 \%$ when compared to above 50 years with $26.1 \%$. The indicators with significant increase in complications was delay in care (pre-operative duration of symptoms) more than 48 hours $56 \%$ (Odds ratio $(\mathrm{OR})=3.56$; 95\% Confidence Interval (CI):1.06-12.02; $\mathrm{P}=0.02)$, the longer duration of operation $61.3 \%(0 \mathrm{R}=3.80,95 \% \mathrm{CI}$ : 1.01-14.61, $\mathrm{p}=0.04)$. In relation to sex of patient, complications were more prevalent to female $61.5 \%(\mathrm{OR}=2.05$; $95 \% \mathrm{CI}$ : $0.58-7.18)$, but this was not statistically significant. Other parameters with positive

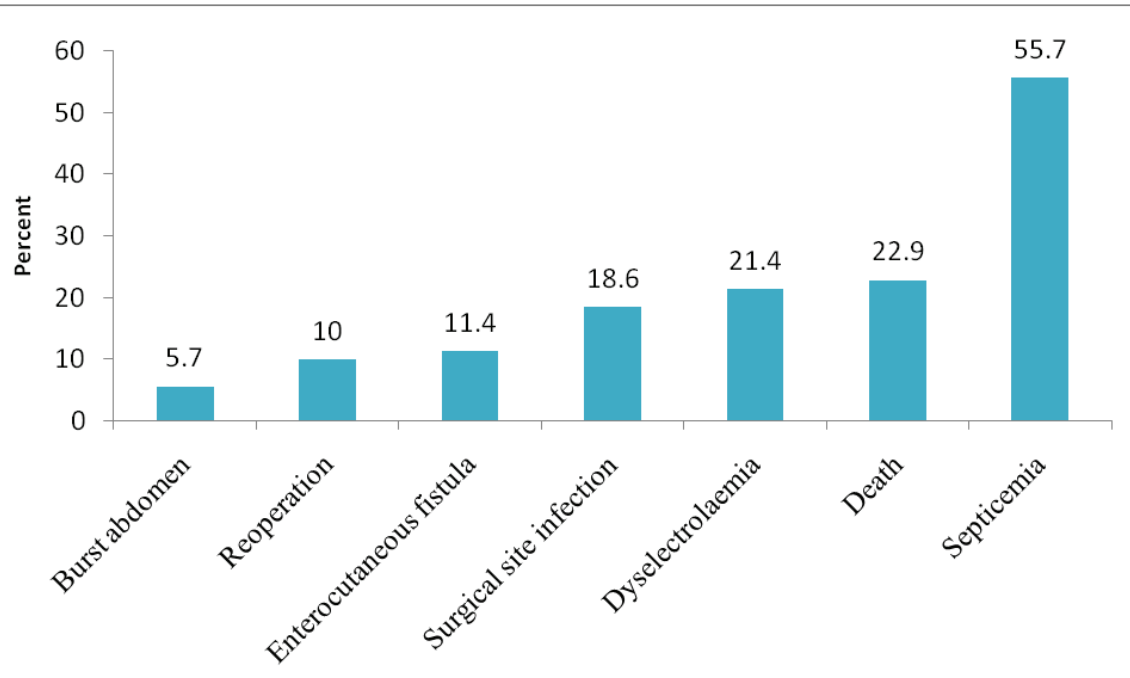

Figure 1: The short term outcomes for operated patients with peritonitis at $\mathrm{KCMC}(\mathrm{n}=70)$.

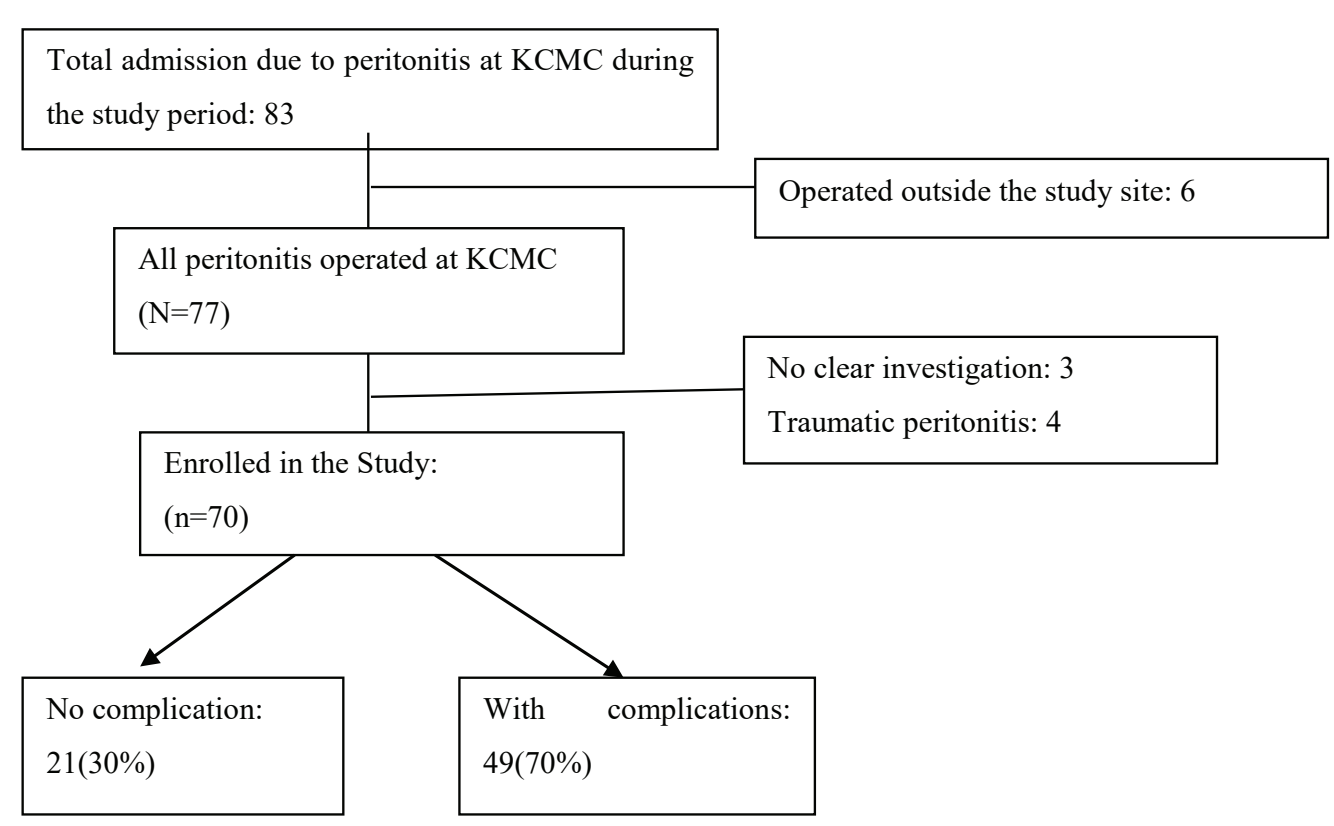

Figure 2: The short term outcomes for operated patients with peritonitis at $\operatorname{KCMC~}(n=70)$. 
Table 1: Socio-demographic characteristics of the study participants $(n=70)$.

\begin{tabular}{|c|c|c|c|}
\hline Variables & Categories & $\mathbf{n}$ & $\%$ \\
\hline \multirow{3}{*}{ Age in years } & [Median, IQR] & {$[41,22-56]$} & \\
\hline & $\geq 50$ & 47 & 67.1 \\
\hline & $>50$ & 23 & 32.9 \\
\hline \multirow{2}{*}{ Sex of the participant } & Male & 57 & 81.4 \\
\hline & Female & 13 & 18.6 \\
\hline \multirow{4}{*}{ Education background } & Informal & 9 & 12.9 \\
\hline & Primary & 43 & 61.4 \\
\hline & Secondary & 12 & 17.1 \\
\hline & College/university & 6 & 8.6 \\
\hline \multirow{3}{*}{ Employment status } & Employed & 9 & 12.9 \\
\hline & Unemployed & 46 & 65.7 \\
\hline & Child & 15 & 21.4 \\
\hline \multirow{3}{*}{ Place of residence } & Moshi urban & 18 & 25.7 \\
\hline & $\begin{array}{l}\text { Other Districts of } \\
\text { Kilimanjaro }\end{array}$ & 37 & 52.9 \\
\hline & Outside Kilimanjaro & 15 & 21.4 \\
\hline \multirow{2}{*}{ Smoke cigarette } & No & 60 & 85.7 \\
\hline & Yes & 10 & 14.3 \\
\hline \multirow{2}{*}{ Alcohol drink } & No & 53 & 75.7 \\
\hline & Yes & 17 & 24.3 \\
\hline
\end{tabular}

association with complications but were not statistically significant includes generalized peritonitis $47.6 \%$ (OR=1.21; 95\%CI: 0.25-5.94), character of peritoneal fluid including purulent $51.2 \%$, faecal $42.9 \%$, and haemorrhagic 60\%; Gastrointestinal (GIT) perforation $51.3 \%$ $(\mathrm{OR}=1.46$; 95\%CI: 0.56-3.81), and gangrenous bowel 71.4\% (OR=3.13; 95\%CI: 0.54-17.97).

Regarding laboratory parameters associated with complications table 3 is concerned. Low potassium was a significant parameter associated with complications $65.2 \%(\mathrm{OR}=3.08,95 \% \mathrm{CI}$ : $1.02-9.59$, $\mathrm{P}=0.04)$. Other laboratory indicators for complications included low $\mathrm{Hb} 48.6 \%$ (OR=1.14; 95\%CI: 0.44-2.93), low sodium 50\% (OR=1.13; 95\%CI: $0.42-3.03$ ), and TLC less than $4 \times 10^{9}$ units per liter $66.7 \%$ $(\mathrm{OR}=1.90$; 95\%CI: 0.15-23.68).

\section{Prognostic indicators for mortality among operated patients with peritonitis}

Considering the associated parameters, we categorized these into non-laboratory and laboratory indicators as described in tables 4 and 5 .

Non-laboratory prognostic indicators for mortality among patients operated due to peritonitis, are shown in table 4 . The significant presented indicators for mortality were comorbidity with 7.80 folds in increase of mortality in the crude odds ratio, the comorbidity remained significant even after adjusting other indicators in the multivariate model (Adjusted Odds Ratio $(\mathrm{AOR})=3.02$; 95\%CI: 2.2542.90). Other indicators with positive association included high Pulse Rates (PR) $>100 \mathrm{bpm}$ (Crude Odds Ratio $(\mathrm{COR})=4.04$; 95\%CI: 1.09 15.02), but this indicated weak association after adjusting with other indicators (AOR=3.32, 95\%CI: 0.91-12.08), high Respiratory Rates (RR) above 30 beats per minutes (bpm) $(\mathrm{COR}=5.67$; 95\%CI: 1.04 -
Table 2: Prognostic indicators (Non-laboratory parameters) for complications among operated patients with peritonitis $(\mathrm{N}=70)$.

\begin{tabular}{|c|c|c|c|c|}
\hline \multirow{2}{*}{$\begin{array}{l}\text { Prognostic } \\
\text { indicators }\end{array}$} & \multirow{2}{*}{\begin{tabular}{|c|} 
All patients \\
$\mathbf{N}$ \\
\end{tabular}} & \multirow{2}{*}{$\begin{array}{c}\begin{array}{c}\text { With } \\
\text { complication } \\
(n=33)\end{array} \\
n(\%)\end{array}$} & \multicolumn{2}{|c|}{ Statistical estimate } \\
\hline & & & OR(95\%Cl) & P-value \\
\hline \multicolumn{5}{|c|}{ Age group years } \\
\hline$\geq 50$ & 47 & $27(57.4)$ & 1.00 & \\
\hline$>50$ & 23 & $6(26.1)$ & $\begin{array}{c}0.26(0.08- \\
0.83)\end{array}$ & 0.014 \\
\hline \multicolumn{5}{|c|}{ Sex } \\
\hline Male & 57 & $25(43.9)$ & 1.00 & \\
\hline Female & 13 & $8(61.5)$ & $\begin{array}{c}2.05(0.58- \\
7.18)\end{array}$ & 0.252 \\
\hline \multicolumn{5}{|c|}{ Peritonitis } \\
\hline Localized & 7 & $3(42.9)$ & - & \\
\hline Generalized & 63 & $30(47.6)$ & $\begin{array}{c}1.21(0.25- \\
5.94)\end{array}$ & 0.812 \\
\hline \multicolumn{5}{|c|}{ Character of peritoneal fluid } \\
\hline Clear & 13 & $4(30.8)$ & 1.00 & \\
\hline Purulent/turbid & 43 & $22(51.2)$ & $\begin{array}{c}2.36(0.61- \\
9.12)\end{array}$ & 0.200 \\
\hline Faecal & 7 & $3(42.9)$ & $\begin{array}{c}1.69(0.24- \\
12.08)\end{array}$ & 0.598 \\
\hline Haemorrhagic & 5 & $3(60.0)$ & $\begin{array}{c}3.38(0.34- \\
33.27)\end{array}$ & 0.268 \\
\hline Others & 2 & $1(50.0)$ & $\begin{array}{c}2.25(0.10- \\
52.39)\end{array}$ & 0.603 \\
\hline \multicolumn{5}{|c|}{ Pre-operative duration of symptoms } \\
\hline Less than 24 & 1 & $0(0.0)$ & & \\
\hline 24 to 48 & 19 & $5(26.3)$ & 1.00 & \\
\hline More than 48 & 50 & $28(56.0)$ & $\begin{array}{c}3.56(1.06- \\
12.02)\end{array}$ & 0.028 \\
\hline \multicolumn{5}{|c|}{ GIT perforation } \\
\hline No & 31 & 13(41.9) & 1.00 & \\
\hline Yes & 39 & 20(51.3) & $\begin{array}{c}1.46(0.56- \\
3.81)\end{array}$ & 0.439 \\
\hline \multicolumn{5}{|c|}{ Gangrenous bowel } \\
\hline No & 57 & $28(49.1)$ & 1.00 & \\
\hline Yes & 13 & $5(38.5)$ & $\begin{array}{c}3.13(0.54- \\
17.97)\end{array}$ & 0.178 \\
\hline \multicolumn{5}{|c|}{ Duration of operation } \\
\hline Less than 2 & 17 & $5(29.4)$ & 1.00 & \\
\hline 2 to 3 & 31 & 19(61.3) & $\begin{array}{c}3.80(1.01- \\
14.61)\end{array}$ & 0.045 \\
\hline More than 3 & 22 & $9(40.9)$ & $\begin{array}{c}1.66(0.42- \\
6.56)\end{array}$ & 0.463 \\
\hline \multicolumn{5}{|c|}{ Co-morbidity } \\
\hline No & 43 & $23(53.5)$ & 1.00 & \\
\hline Yes & 27 & $10(37.0)$ & $\begin{array}{c}0.51(0.19- \\
1.40)\end{array}$ & 0.182 \\
\hline
\end{tabular}


Table 3: Prognostic indicators (Laboratory parameters) for complications among operated patients with peritonitis ( $\mathrm{N}=70$ ).

\begin{tabular}{|c|c|c|c|c|}
\hline \multirow{2}{*}{ Prognostic indicators } & \multirow{2}{*}{$\begin{array}{c}\text { All patients } \\
\mathbf{N}\end{array}$} & \multirow{2}{*}{$\begin{array}{c}\text { With Complication }(n=33) \\
n(\%)\end{array}$} & \multicolumn{2}{|c|}{ Statistical estimate } \\
\hline & & & OR(95\%Cl) & P-value \\
\hline \multicolumn{5}{|l|}{ Hb level } \\
\hline Normal & 33 & $15(45.5)$ & 1.00 & \\
\hline Low & 37 & $18(48.6)$ & $1.14(0.44-2.93)$ & 0.791 \\
\hline \multicolumn{5}{|c|}{ Haematocrit (\%) } \\
\hline Less than 25 & 5 & $2(40.0)$ & $0.63(0.09-4.33)$ & 0.638 \\
\hline 25 to 40 & 39 & $20(51.3)$ & 1.00 & \\
\hline More than 40 & 26 & $11(42.3)$ & $0.70(0.25-1.92)$ & 0.481 \\
\hline \multicolumn{5}{|c|}{$\mathrm{TLC}\left(\times 10^{9} / \mathrm{L}\right)$} \\
\hline Less than 4 & 3 & $2(66.7)$ & $1.90(0.15-23.68)$ & 0.613 \\
\hline 4 to 11 & 37 & 19(51.4) & 1.00 & \\
\hline More than 11 & 30 & $12(40.0)$ & $0.33(0.025-4.40)$ & 0.357 \\
\hline \multicolumn{5}{|c|}{ Sodium (mmol/L) } \\
\hline Less than 135 & 30 & $15(50.0)$ & $1.13(0.42-3.030$ & 0.815 \\
\hline 136 to 150 & 34 & $16(47.1)$ & 1.00 & \\
\hline More than 150 & 6 & $2(33.3)$ & $0.56(0.09-3.61)$ & 0.538 \\
\hline \multicolumn{5}{|c|}{ Potassium (mmol/L) } \\
\hline Less than 3.8 & 23 & $15(65.2)$ & $3.08(1.02-9.59)$ & 0.040 \\
\hline $3.8-5.10$ & 37 & $14(37.8)$ & 1.00 & \\
\hline Above 5.10 & 10 & $4(40.0)$ & $1.10(0.26-4.64)$ & 0.901 \\
\hline \multicolumn{5}{|c|}{ Creatinine $(\mu \mathrm{mol} / \mathrm{L})$} \\
\hline less than 62 & 14 & $6(42.9)$ & $0.59(0.16-2.13)$ & 0.416 \\
\hline $62-106$ & 34 & 19(55.9) & 1.00 & \\
\hline More than 106 & 22 & $8(36.4)$ & $0.45(0.15-1.40)$ & 0.157 \\
\hline
\end{tabular}

31.01), this also remained not significant in the multivariate model $(\mathrm{AOR}=3.93,0.73-21.21)$. Patients aged more than 50 years had 2.6 times increased risk for mortality when compared to patients aged 50 years and below $(\mathrm{COR}=2.60$; 95\% CI: $0.80-8.45)$. Abdominal tumor, malignant had 7.04 folds increase in mortality but this was lacking statistical evidence in the multivariate model $(\mathrm{AOR}=7.04$; $95 \% \mathrm{CI}$ : 0.32-156.78).

Laboratory prognostic indicators for mortality are presented in table 5. High Creatinine above 106 micromol per litre and low Haemoglobin $(\mathrm{Hb})$ were the significant laboratory prognostic indicator for mortality (COR=6.25; 95\%CI: $1.45-26.92)$ and $\mathrm{COR}=5.42$; 95\%CI: 1.28-23.01), even after adjusting with possible interactions we found powerful association in both high creatinine and low $\mathrm{Hb}$, however, these were not statistically significant $(\mathrm{AOR}=4.53 ; 95 \% \mathrm{CI}: 0.90-22.77$ ) and $(\mathrm{AOR}=4.20 ; 95 \% \mathrm{CI}: 0.93-19.02)$ respectively. Other parameters including Sodium, Potassium, TLC, and haematocrit had positive association with mortality though these were lacking statistical evidence.

\section{Complications and comorbidity associated with postoperative mortality among patients with peritonitis}

The sub-analysis was done to associate complications and comorbidity that associated with mortality among patients operated due to peritonitis. In the sub-analysis, patients presented with severe anaemia pre-operatively had 5.88 folds in increase of mortality, and this remained most significant indicators for mortality in the multivariate analysis (AOR=9.89, 95\%CI: 1.12-87.51). Patients who developed dyselectrolaemia after operation had 6.71 high increases in risk of mortality when compared to the counterpart $(\mathrm{COR}=6.71,1.70$ -
26.50); and this continued to be significant indicator for mortality in the multivariate analysis (AOR=9.27; 95\%CI: 1.21-70.83). Patients who were re-operated had 5.67 folds in increase of mortality when compared to non re-operated patients and this was significant in the crude analysis (COR=5.67, 95\%CI: 1.03-31.00) though in the multivariate analysis this was not significant $(\mathrm{AOR}=4.16,95 \% \mathrm{CI}$ : 0.25 69.53), (Table 6).

\section{Discussion}

The total number of 70 participants was recruited, with predominance of male observed giving a male to female ratio of 4.4:1. The predominance of male sex for general surgical pathology was even documented by other studies $[6,8]$. The majority were patients aged $<50$ years similar to study in Kenya [4]. Out of 70 patients, 33 (47.1\%) developed postoperative complications and $16(22.9 \%)$ patients died.

In this study, the major influence of mortality was comorbidity and postoperative complications similar to study in Tanzania [6].

The overall complication in this study was $47.1 \%$. This is consistency to study conducted in neighboring country in Kenya [4]. Having similar proportion of complications can be explained due to nature of the clients enrolled in the study who shared common lifestyle. However, other study in middle income countries in India also reported similar findings $36.0 \%$ [5]. The different can be explained due to early presentation to care and management; in the current study majority of the clients delayed in seeking care in which about $56 \%$ of patients presented after 48 hours since the onset of the symptoms, a situation that resulted an increase in risk of complications as reported in this study. 
Table 4: Logistic regression analysis of the prognostic indicators (Non laboratory parameters) for mortality among operated patients with peritonitis $(\mathrm{N}=70)$.

\begin{tabular}{|c|c|c|c|c|}
\hline \multirow[t]{2}{*}{ Prognostic Indicators } & \multirow{2}{*}{$\begin{array}{c}\text { All patients } \\
\mathbf{N} \\
\end{array}$} & \multirow{2}{*}{$\begin{array}{c}\text { Complication ( } n=16) \\
n(\%)\end{array}$} & \multicolumn{2}{|c|}{ Statistical estimate } \\
\hline & & & $\operatorname{COR}(95 \% \mathrm{Cl})$ & $\operatorname{AOR}(95 \% \mathrm{Cl})$ \\
\hline \multicolumn{5}{|c|}{ Age group(years) } \\
\hline$\geq 50$ & 47 & $3(17.0)$ & 1.00 & \\
\hline$>50$ & 23 & $3(34.8)$ & $2.60(0.80-8.45)$ & \\
\hline \multicolumn{5}{|c|}{ Character of peritoneal fluid } \\
\hline Clear & 13 & $1(7.7)$ & 1.00 & \\
\hline Purulent/turbid & 43 & $9(20.9)$ & $3.18(0.35-29.00)$ & $3.46(0.14-8.51)$ \\
\hline Faecal & 7 & $4(57.1)$ & $16.0(0.72-35.60)$ & $2.84(1.21-9.8)$ \\
\hline Haemorrhagic & 5 & $1(20.0)$ & $3.00(0.13-68.69)$ & $1.64(0.04-71.33)$ \\
\hline Others & 2 & $1(50.0)$ & $12.00(0.23-611.85)$ & $5.41(0.02-37.93)$ \\
\hline \multicolumn{5}{|c|}{ PR(bpm) } \\
\hline$<100$ & 35 & $4(11.4)$ & 1.00 & \\
\hline$>100$ & 35 & $12(34.3)$ & $4.04(1.09-15.02)$ & $3.32(0.91-12.08)$ \\
\hline \multicolumn{5}{|c|}{$\mathbf{R R}(\mathbf{b p m})$} \\
\hline Below 30 & 63 & 12(19.0) & 1.00 & \\
\hline Above $30 \mathrm{~b}$ & 7 & $4(57.1)$ & $5.67(1.04-31.01)$ & $3.93(0.73-21.21)$ \\
\hline \multicolumn{5}{|c|}{ Shock } \\
\hline Yes & 11 & $4(36.4)$ & $2.25(0.55-9.13)$ & $1.63(0.47-24.86)$ \\
\hline No & 59 & $12(20.3)$ & 1.00 & \\
\hline \multicolumn{5}{|c|}{ Duration of operation(hrs) } \\
\hline Less than 2 & 17 & $4(23.5)$ & 1.00 & \\
\hline 2 to 3 & 31 & $6(19.4)$ & $0.78(0.18-3.32)$ & $0.22(0.01-3.88)$ \\
\hline More than 3 & 22 & $6(27.3)$ & $1.22(0.28-5.36)$ & $0.12(0.01-2.55)$ \\
\hline \multicolumn{5}{|c|}{ Co-morbidity } \\
\hline No & 43 & $4(9.3)$ & 1.00 & \\
\hline Yes & 27 & $12(44.4)$ & $7.80(1.90-31.96)$ & $3.02(2.25-42.90)$ \\
\hline \multicolumn{5}{|c|}{ Abdominal tumour } \\
\hline Non-malignant & 65 & $13(20.0)$ & 1.00 & \\
\hline Malignant & 5 & $3(60.0)$ & $6.00(0.84-42.73)$ & $7.04(0.32-156.78)$ \\
\hline
\end{tabular}

The most reported complications in the current study comprised of septicemia, dyselectrolemia, surgical site infection, enterocutaneous fistula, re-operation and burst abdomen. The nature of complications in this study is almost similar to that reported in Pakistan, India and Kenya [3-5]. This implies that varieties of complications due to peritonitis after operation may not be influenced by environmental exposures or ethnicity rather the patient's altitude and the quality of care that may help to reduce the magnitude of the pertained problem.

In regards to mortality; we found the mortality rate of $22.9 \%$. This was high when compared to other studies in Tanzania [6] and India [9] which reported the overall mortality of $15.46 \%$ and $10 \%$ respectively. This difference could be explained by the presence of well-equipped established modern accident and emergency department in the study centers as reported by the previous studies where emergency service is provided. Our finding is consistency with other studies in India which found mortality of $25 \%$ [8].

Higher complications and mortality in the current study could be explained by late presentation to the health facility by majority of patients and presence of co-morbid illness, a situation which further complicates effective management. In this study, patients with preoperative duration of symptoms for more than 48 hours had increased risk of complications compared to the counterpart. Similarly, studies in India and Tanzania which found that majority of patients who presented late in care were more likely to increase risk of complications [6,9]. Ideally, patients who delayed in presentation for treatment fared the worst, a situation which further complicates effective management.

The current study found the time of surgery was associated with complications. The complications were significantly high in the group of patients where surgery lasted more than 2 hours, and this was statistically significant similar to the finding India [5].

In this study, preoperative serum Potassium levels had affected the complications. Hypokaelemia of less than $3.8 \mathrm{mmol} / \mathrm{L}$ was significantly related to complications contrary to findings by Khan PS, et al., in India where Potassium levels had no relation at all to complications [5]. However, despite the difference in finding between the current and that reported by Khan PS, et al. Potassium is still one of the parameters in the Acute Physiology and Chronic Health Evaluation (APACHE) scoring system to predict the outcome.

The study showed that, age more than 50 years had complications of $26.1 \%$, however, this is contrary to other studies that concluded age more than 50 years is related to high overall complications of $47.1 \%$ and 50\% like studies done in Kenya and in India respectively [4,9]. 
Table 5: Logistic regression analysis of the prognostic indicators (Laboratory parameters) for mortality among operated patients with peritonitis $(\mathrm{N}=70)$.

\begin{tabular}{|c|c|c|c|c|}
\hline \multirow{2}{*}{ Prognostic Indicators } & \multirow{2}{*}{$\begin{array}{c}\text { All patients } \\
\mathrm{N}\end{array}$} & \multirow{2}{*}{$\begin{array}{c}\text { Mortality (n=16) } \\
n(\%)\end{array}$} & \multicolumn{2}{|c|}{ Statistical estimate } \\
\hline & & & $\operatorname{COR}(95 \% \mathrm{Cl})$ & AOR(95\%Cl) \\
\hline \multicolumn{5}{|c|}{$\mathrm{Hb}(\mathrm{g} / \mathrm{dl})$} \\
\hline Normal & 33 & $3(9.1)$ & 1.00 & \\
\hline Low & 37 & $13(35.1)$ & $5.42(1.28-23.01)$ & $4.20(0.93-19.02)$ \\
\hline \multicolumn{5}{|c|}{ Haematocrit (\%) } \\
\hline Less than 25 & 5 & $3(60.0)$ & $4.35(0.58-32.42)$ & \\
\hline 25 to 40 & 39 & $10(25.6)$ & 1.00 & \\
\hline More than 40 & 26 & $3(11.5)$ & $0.38(0.09-1.58)$ & \\
\hline \multicolumn{5}{|c|}{$\operatorname{TLC}\left(\times 10^{9} / \mathrm{L}\right)$} \\
\hline Less than 4 & 3 & $0(0.0)$ & - & \\
\hline 4 to 11 & 37 & $8(21.6)$ & 1.00 & \\
\hline More than 11 & 30 & $8(26.7)$ & $1.32(0.42-4.11)$ & \\
\hline \multicolumn{5}{|c|}{ Sodium (mmol/L) } \\
\hline Less than 135 & 30 & $8(26.7)$ & $2.11(0.59-7.52)$ & $1.35(0.31-5.92)$ \\
\hline 136 to 150 & 34 & $5(14.7)$ & 1.00 & \\
\hline More than 150 & 6 & $3(50.0)$ & $5.80(0.80-42.23)$ & $3.58(0.42-30.50)$ \\
\hline \multicolumn{5}{|c|}{ Potassium(mmol/L) } \\
\hline Less than 3.8 & 23 & $3(13.0)$ & $0.47(0.11-2.00)$ & $0.34(0.07-1.82)$ \\
\hline $3.8-5.10$ & 37 & $9(24.3)$ & 1.00 & \\
\hline Above 5.10 & 10 & $4(40.0)$ & $2.07(0.46-9.32)$ & $1.12(0.18-7.10)$ \\
\hline \multicolumn{5}{|c|}{ Creatinine $(\mu \mathrm{mol} / \mathrm{L})$} \\
\hline less than 62 & 14 & $2(14.3)$ & $1.25(0.20-7.91)$ & $1.28(0.20-8.20)$ \\
\hline $62-106$ & 34 & $4(11.8)$ & 1.00 & \\
\hline $106-212$ & 22 & $10(45.5)$ & $6.25(1.45-26.92)$ & $4.53(0.90-22.77)$ \\
\hline
\end{tabular}

But in this study the lower complications in the elderly probably was affected by small number of participants in the elderly group.

This study found other indicators for complications include female 61.5\%, high PR 48.6\%, purulent peritoneal fluid 51.2\%, GIT perforation $51.3 \%$, gangrenous bowel $71.4 \%$, TLC (less than $4 \times$ $109 / \mathrm{L}$ ) $66.7 \%$, sodium less than $135 \mathrm{mmol} / \mathrm{L}$ (50\%), all these were not statistically significant when compared to previous study done by Khan et al., which reported significant association with low $\mathrm{Hb} 36 \%$, Sodium level less than $135 \mathrm{mmol} / \mathrm{L}(42.9 \%)$ and purulent peritoneal fluid $38.7 \%$ [5].

In this study, presence of comorbidity was shown to have a significant effect on the mortality where $44.4 \%$ of patients with comorbidity died. A similar influence of comorbidity on the mortality was reported by Mabewa A, et al. with mortality of $60 \%$ [6]. This may be due to less attention that is given to comorbidity in the setting of surgical emergency and therefore co-morbidity may be overlooked leading to increased risk of mortality. The current study again found high creatinine, low $\mathrm{Hb}$, high $\mathrm{PR}$ and high $\mathrm{RR}$ were significantly associated with mortality, corresponding to findings in India [5].

Looking into age of patients, this study showed patients with age less than 30 years was significantly associated with mortality of $25 \%$ than elderly group aged $>50$ years $(15.8 \%)$ different from previous study in Karnataka where they found patients aged $>50$ years were significantly associated with mortality [10]. The difference in mortality may be explained by small number of participants in elderly group aged $>50$ years in the present study.

In this study mortality was also seen in patients with faecal peritoneal soakage and presence of abdominal malignancy, similar to the findings in India [8]. However, both findings were not conclusive due to small number of patients with malignancy.

\section{Conclusion}

Delays in care, longer duration of operation and low serum Potassium are the prognostic indicators for the post-operative complications. Comorbidity and postoperative complications such as dyselectrolaemia had influence for the mortality. Correct prediction of these adverse outcomes will help to institute better management for the patients with peritonitis. Moreover, further prospective study is required to validate the individual factors identified in this study.

\section{Ethical Consideration}

Ethical clearance and approval with certificate number 2361 was obtained from Kilimanjaro Christian Medical College Research Ethics and Review Committee (CRERC). The study observed confidentiality and privacy of the subjects. No participant's name was used. Instead, unique identifiers were used. Also, no participant incurred either laboratory or radiological investigations expenses.

Informed consent process was provided to all participants and clear information was given following written consent. The document was prepared in Swahili for convenience.

\section{Consent for Publication}

Not applicable

\section{Availability of Data and Materials}

All data and materials concerning this research article are available for sharing if needed. 
Table 6: Complications and co-morbidity associated with post-operative mortality among patients with peritonitis ( $\mathrm{N}=70)$.

\begin{tabular}{|c|c|c|c|c|c|}
\hline \multirow{2}{*}{ Factors } & \multirow{2}{*}{ All patients } & \multicolumn{2}{|c|}{ Post-operative outcome } & \multicolumn{2}{|c|}{ Estimated Odds Ratio } \\
\hline & & Survivor $(n=54)$ & Died $(n=16)$ & COR $(95 \% \mathrm{Cl})$ & AOR $(95 \% \mathrm{Cl})$ \\
\hline \multicolumn{6}{|c|}{ Surgical site infection } \\
\hline No & 57 & $44(77.2)$ & $13(22.8)$ & & \\
\hline Yes & 13 & $10(76.9)$ & $3(23.1)$ & $1.02(0.24-4.29)$ & $0.96(0.11-8.60)$ \\
\hline \multicolumn{6}{|c|}{ Septiceamia } \\
\hline No & 31 & $26(83.9)$ & $5(16.1)$ & & \\
\hline Yes & 39 & $28(71.8)$ & $11(28.2)$ & $2.04(0.61-6.82)$ & $0.75(0.15-3.90)$ \\
\hline \multicolumn{6}{|c|}{ Burst abdomen } \\
\hline No & 66 & $51(77.3)$ & $15(22.7)$ & & \\
\hline Yes & 4 & $3(75.0)$ & $1(25.0)$ & $1.13(0.11-11.91)$ & $0.09(0.01-7.08)$ \\
\hline \multicolumn{6}{|c|}{ Fistula, enterocutaneous fistula } \\
\hline No & 62 & $50(80.6)$ & $12(19.4)$ & & \\
\hline Yes & 8 & $4(50.0)$ & $4(50.0)$ & $4.17(0.86-20.16)$ & $2.72(0.23-32.56)$ \\
\hline \multicolumn{6}{|c|}{ Re-operated } \\
\hline No & 63 & $51(81.0)$ & $12(19.0)$ & & \\
\hline Yes & 7 & $3(42.9)$ & $4(57.1)$ & $5.67(1.03-31.00)$ & $4.16(0.25-69.53)$ \\
\hline \multicolumn{6}{|c|}{ Dyselectrolemia } \\
\hline No & 55 & $47(85.5)$ & $8(14.5)$ & & \\
\hline Yes & 15 & $7(46.7)$ & $8(53.3)$ & $6.71(1.70-26.50)$ & $9.27(1.21-70.83)$ \\
\hline \multicolumn{6}{|c|}{ Hypertension } \\
\hline No & 64 & $50(78.1)$ & $14(21.9)$ & & \\
\hline Yes & 6 & $4(66.7)$ & $2(33.3)$ & $1.79(0.29-10.98)$ & $9.14(0.56-150.63)$ \\
\hline \multicolumn{6}{|c|}{ Diabetes mellitus } \\
\hline No & 68 & $52(76.5)$ & $16(23.5)$ & 1.00 & \\
\hline Yes & 2 & $2(100)$ & $0(0.0)$ & - & \\
\hline \multicolumn{6}{|c|}{ Renal failure } \\
\hline No & 66 & $53(80.3)$ & $13(19.7)$ & & \\
\hline Yes & 4 & $1(25.0)$ & $3(75.0)$ & $12.23(1.03-145.85)$ & $4.84(0.22-106.52)$ \\
\hline \multicolumn{6}{|c|}{ Severe anaemia } \\
\hline No & 59 & $49(83.1)$ & $10(16.9)$ & & \\
\hline Yes & 11 & $5(45.5)$ & $6(54.5)$ & $5.88(1.37-25.25)$ & $9.89(1.12-87.51)$ \\
\hline \multicolumn{6}{|c|}{ Heart failure } \\
\hline No & 67 & $54(80.6)$ & $13(19.4)$ & 1.00 & \\
\hline Yes & 3 & $0(0.0)$ & $3(100.0)$ & - & \\
\hline
\end{tabular}

\section{Competing Interests}

There are no conflicts of interest regarding this paper to be disclosed.

\section{Funding}

Not applicable.

\section{Author's Contribution}

NM designed the study, wrote the manuscript, collected samples from patients and participated in data collection. $\mathrm{DM}, \mathrm{KC}, \mathrm{AH}$ and $\mathrm{SC}$ participated in designing of the study and editing the manuscript. JA compiled and analyzed final data. All authors have read and approved the manuscript.

\section{Acknowledgement}

Thanks to our colleagues at General Surgery Department in KCMC for their constructive contributions. Our sincere acknowledgement goes to KCMUCo and KCMC management for allowing preparation of this work. We are grateful to our patients for their understanding and acceptance to participate in this study.

\section{References}

1. Ordonez CA, Puyana JC (2006) Management of peritonitis in the critically ill patient. Surg Clin North Am 86: 1323-1349.

2. Thirumalagiri VR, Reddy SRJ, Chandra HT (2017) Acute peritonitis secondary to hollow viscous perforation : a clinical study. Int Surg J 4: 2262-2269.

3. Memon AA, Siddiqui FG, Abro AH, Agha AH, Lubna S, et al. (2012) An audit of secondary peritonitis at a tertiary care university hospital of Sindh, Pakistan. World J Emerg Surg 7: 1-5. 
4. Wabwire B, Saidi H (2014) Stratified outcome evaluation of peritonitis. Ann African Surg 11: 29-34.

5. Khan PS, Dar LA, Hayat H (2013) Predictors of mortality and morbidity in peritonitis in a developing country. Ulus Cer Derg 29: 124-130.

6. Mabewa A, Seni J, Chalya PL, Mshana SE, Gilyoma JM (2015) Etiology, treatment outcome and prognostic factors among patients with secondary peritonitis at Bugando Medical Centre, Mwanza, Tanzania. World J Emerg Surg 47: 1-7.

7. Doklestić $S K$, Bajec DD, Djukić RV, Bumbaširević $\mathrm{V}$, Detanac $A D$, et al. (2014) Secondary peritonitis -evaluation of 204 cases and literature review. J Med Life 7: 132-138.
8. Jain S, Jain M, Jain R (2015)Validation of Mannheim peritonitis index in a tertiary care center in Rajasthan. Int J Med Sci Public Heal 4: 664-668.

9. Jhobta RS, Attri AK, Kaushik R, Sharma R, Jhobta A (2006) Spectrum of perforation peritonitis in India--review of 504 consecutive cases. BioMed Cent Res 4: 2-5.

10. Chandrashekar N, Prabhakar G, Gurukiran C, Shivakumarappa G, Naveen $\mathrm{H}$ (2013) Study of progostic factors in perforative peritonitis. J Evol Med Dent Sci 2: 5568-5574. 